Bradbury, Mark. D., Battaglio, R. P., and Crum, J. L. (2010) Continuity amid discontinuity? George W. Bush, Federal Employment Discrimination, and "Big Government Conservatism." Review of Public Personnel Administration, 30(4): 445-466. (Dec 2010). ISSN: 0734-371X doi:10.1177/0734371X10381486

\title{
Continuity Amid Discontinuity? George W. Bush, Federal Employment Discrimination, and "Big Government Conservatism"
}

\author{
Mark D. Bradbury, R. Paul Battaglio, Jr., \\ and John L. Crum
}

\begin{abstract}
One of the major substantive components of "big government conservatism" was a decided predisposition against public employee unions, toward privileging managerial discretion, and yet still maintaining equal opportunity in the workplace. However, could this predisposition be resolved in practice without harming federal employees' rights, benefits, and morale in the workplace? To address this question, this article examines whether the attitudes of federal employees toward variants of subjective discrimination in the workplace changed significantly during the George W. Bush presidency. We find that trends related to perceptions of retaliation and discrimination have improved in recent years. However, perceptions of retaliation and discrimination are found to exist among minority and female employees and managers in the federal workplace that require vigilance. These results suggest that big government conservatism's predisposition to pursue equal opportunity as opposed to affirmative actionwhile diminishing the power of public employee unions and enhancing managerial prerogatives-either succeeded on its own merits or that the earlier momentum could not be stopped.
\end{abstract}

\section{Keywords}

merit protection, employee discrimination, civil service reform, George W. Bush 
Media accounts of the Bush administration were consistently rife with charges of shoddy treatment of federal workers - and especially scientists and regulatorswho disagreed with its deregulatory (some would say, antiregulatory) philosophy. As the editors of this symposium note in their introduction, President Bush's vision of "big government conservatism" also involved using the power of the federal government to hive off federal jobs to the private sector to, among other things, work around government agencies, decrease dependence on the state, and build political support among contractors for the Republican party. As they also note, packaged within the president's big government conservative agenda was a decided effort to enhance managerial prerogative, foster equality of opportunity rather than equality of outcome, and diminish the power of public sector unions.

However, could these various agendas be integrated in practice and without demoralizing federal employees who might feel that their rights and protections as employees were under assault? As both Jim Thompson and Ed Kellough and his colleagues report in their contributions to this symposium, and as we shall review briefly below, the Bush years witnessed a sustained and persistent effort to push ahead the managerial prerogative component of Bush's big government conservative human resource management (HRM) agenda. Less clear to this point in the other articles as well as in the HRM literature generally is whether managerial prerogative was allowed to trump employee rights, antidiscrimination, and benefit protections during the Bush years.

To address this question, this article relies on results from an expansive federal government employee survey conducted to examine the extent to which they perceived inappropriate reprisals for employees who engaged in whistle-blowing, reported unwanted sexual attention, and were denied benefits due to unlawful discrimination during the Bush years. Our analysis compares employee attitudes at three points during the presidency of George W. Bush to provide a compelling bottom-up assessment of the possible effects of that administration's approach to HRM on employees' attitudes. In using such a research design, we contend that, in effect, a pretest-posttest situation is created because the 2000 survey covers the Clinton years while the subsequent surveys track developments and trends in the Bush era. Although hardly a longitudinal design, this approach does allow inferences about the extent to which the Bush administration was able to advance its agenda without compromising - or being able to compromiseemployee protections or the perceptions that those rights were endangered. 
Overall, our analysis suggests that although trends related to perceptions of retaliation and discrimination have improved in recent years, models that account for demographics indicate that minority and female employees perceive that unlawful discrimination remains in the federal workplace. These results suggest that big government conservatism's predisposition to pursue equal opportunity as opposed to affirmative action while diminishing the power of public employee unions and enhancing managerial prerogatives may have succeeded. What remains unclear, however, is where to attribute these results. Was it that the failures and reversals of Bush signature initiatives chronicled in earlier articles in this symposium attenuated declines in employee fortunes? Or was it that the momentum of progress made during the Clinton years had become so institutionalized that employee protections could not be stopped? These results also suggest, however, that much work remains to be done, as statistically significant and substantively meaningful gender and racial differences existed among respondents to the survey.

The article begins by reviewing and distinguishing between two conceptualizations of discrimination: objective and subjective. With this as conceptual context, the article discusses the data and methods employed to address the primary research question: Did perceptions of subjective discrimination increase significantly during the Bush administration? The article concludes by assessing the implications of the findings for the legacy of big government conservatism under Bush, for the continuing salience of antidiscriminatory efforts in the federal workforce during the Obama administration, and for future HRM research.

\section{Coming to Terms: Two Conceptualizations of Discrimination}

As earlier articles in this symposium have chronicled, the George W. Bush administration championed a variety of innovations and reforms designed to improve the management of the federal government's human resources. As shown in even broader strokes in Exhibit 1, initiatives ranged from large-scale attempts to overhaul the personnel systems of federal agencies-including the National Security Personnel System at the Department of Defense-to reforming of the oft-maligned hiring processes of the federal government and the imposition of market-based principles in a variety of personnel contexts. Notably, the Bush administration oversaw the largest reorganization of the federal executive branch in the modern era by way of the creation of the Department of Homeland Security. Collectively, we expect that these HRM reforms, and the managerial culture instilled by the Bush administration generally, would be interpreted by career civil servants as being hostile to the principles of the federal merit system, especially in their perceptions of discrimination in the workplace. 
President's Management Agenda: An initiative to make the U.S. federal government more efficient and effective. In its drive to make government more "citizen centered, market based, and results oriented," the agenda emphasizes regular performance reviews for departments, increased managerial flexibility, and greater accountability for employees, in all cases drawing on techniques and models popular in the private sector.

Strategic Management of Human Capital: As part of the President's Management Agenda, the Office of Personnel Management (OPM) led the Federal Government's Strategic Management of Human Capital Initiative. Agencies were scored on progress and status in terms of meeting standards and goals they identified for themselves (in consultation with OPM) through their "Proud To Be" plans.

Expansion of Human Resource Flexibilities and Pay for Performance: Examples include the National Security Personnel System at the Department of Defense, MaxHR at the Department of Homeland Security, increased use of the Federal Career Intern Program, direct hire, and Veteran's Employment Opportunity Act.

Hiring Makeovers: Initiatives such as the 45-day hiring model, end-to-end hiring roadmap, tabbed job announcement, and overhaul of USAJOBs.

Establishment of Annual Employee Survey: A requirement for all executive branch agencies to conduct an annual employee survey. Specifically, the agency survey must assess leadership and management practices that contribute to agency performance and employee satisfaction with leadership policies and practices, the work environment, rewards and recognition, the opportunity for professional development and growth, and the opportunity to contribute to achieving organizational mission.

Repeal of Labor-Management Partnerships: Revocation of Clinton-era executive order that created the National Partnership Council and agency-level councils, which were designed to increase union involvement in agency decision making. Competitive Sourcing: Required federal agencies to hold public-private competitions to determine the most effective and efficient ways to carry out government operations. Competitive sourcing is designed to drive cost savings and efficiency by requiring agencies to have employees compete with contractors for jobs that could be performed commercially and then determine which organization can accomplish the work most economically.

Chief Human Capital Officers Act of 2002: Required the heads of 24 executive departments and agencies to appoint or designate chief human capital officers (CHCOs). Each CHCO serves as his or her agency's chief policy advisor on HRM issues and is charged with selecting, developing, training, and managing a high-quality, productive workforce. 
Creation of the Department of Homeland Security: Created the United States Department of Homeland Security in the largest federal government reorganization since the Department of Defense was created via the National Security Act of 1947 (as amended in 1949). The new department assumed a large number of services, offices, and other organizations previously located in other departments, such as the Customs Service, Coast Guard, and U.S. Secret Service.

Federalization of the Airport Screener Workforce: Created the Transportation Security Administration (TSA) within the U.S. Department of Transportation; however, the TSA was later transferred to the Department of Homeland Security with the passage of the Homeland Security Act.

What do we mean by discrimination? The seemingly intractable issue of discrimination in employment has, as noted, two distinct conceptualizations in the literature: objective and subjective (Hopkins, 1980). Objective discrimination is "seen to exist by an observer based on some pre-existing criteria" (Hopkins, 1980, p. 131). It, thus, is perhaps the most familiar to practitioner and academic audiences and is amenable to legal and managerial remedies. This discrimination is the result of actions or forces that are external to the employee (Naff, 2001). The most common types are prohibited by federal law and violations are enforced by the U.S. Equal Employment Opportunity Commission (EEOC). In addition to enforcing all-toofamiliar violations of federal law that prohibit objective discrimination on the basis of a person's race, color, national origin, sex, age, religion, or disability, the EEOC investigates claims of illegal reprisal or retaliation because a person complains about discrimination, files a charge of discrimination, or participates in an employment discrimination investigation or lawsuit. Recently, the U.S. Supreme Court reaffirmed the discriminatory nature of retaliation with regard to sex discrimination in Jackson v. Birmingham Board of Education (2005): "Retaliation against a person because that person has complained of sex discrimination is another form of intentional sex discrimination ... . Retaliation is, by definition, an intentional act” (p. 4; see also Mitchell, 2009). Indeed, EEOC statistics show that the proportion of charges based on retaliation from all relevant statutes has increased notably in recent years, constituting 34.3\% of charges filed in 2008 (U.S. EEOC, 2008).

Distinct from such "actionable" instances of discrimination and retaliation, employees also may perceive that they are the victims of such illegal or inappropriate treatment. This second conceptualization-subjective discrimination-occurs "when an individual or group, on the basis of their own subjective perceptions, define their situation as discriminatory" (Hopkins, 1980, p. 131). Employees may perceive that they are subject to retaliation for participating in such actions as whistle-blowing, assisting in the exercise of a right, refusing to obey an illegal order, or reporting unwanted sexual attention or sexual harassment. Although subjective discrimination is perceptual, rather 
than tangible as with objective discrimination, the effects on the workplace and individual careers can be equally insidious. As Naff argues,

To the extent that perceptions of disparate treatment contribute to the desire of women or people of color to leave government employment, or deter them from applying for promotions, such perceptions make problematic the achievement of a representative bureaucracy. (2001, pp. 133-134)

Such perceptions of discrimination also may affect job satisfaction, motivation, organizational loyalty, and productivity (Naff, 1995). Thus, irrespective of whether the discrimination or retaliation is actionable or merely perceived, the effects present the same highly salient managerial concern, since employees who file retaliation grievances can have diminished job satisfaction, receive lower performance ratings, and exhibit higher absenteeism rates, and this ultimately can result in higher turnover rates (Daley, 2007; Near \& Miceli, 2008). Equally important, the perceived, or real, threat of retaliation can have a chilling effect on the willingness of those who experience or witness illegal discrimination in the workplace to report such behavior in the future (Mitchell, 2009).

\section{Hypotheses}

This study uses measures of subjective discrimination —-that is, perceptions of reprisal and discrimination - to assess changes in federal employee attitudes during the George $\mathrm{W}$. Bush presidency, and suggests that any observed changes are, in part, a reflection of the HRM agenda of that administration. The primary research question of this study is, thus, whether the attitudes of federal workers on issues of subjective discrimination changed significantly during the Bush presidency. We believe that the administration's HRM reform agenda demonstrated a suspicion of governmentcentered strategies and was likely interpreted by career civil servants as being hostile to the principles of the federal merit system (see Exhibit 1). Thus, we hypothesize that federal employees would be more likely to perceive that they were victims of inappropriate reprisal and illegal discrimination in such an environment. ${ }^{1}$

Furthermore, we expect that women and employees of color will be even more likely to express such perceptions, as suggested by previous research (see esp. Jackson \& Newman, 2004; Naff, 2001; Newman, Jackson, \& Baker, 2003; Parmerlee, Near, \& Jensen, 1982). Naff (2001), for example, examined potential barriers to equal employment such as presidential ideology, supervisors' attitudes, the possibility of a glass-ceiling effect, the probability of disciplinary action, perceptions of discrimination, and sexual harassment (see also Naff, 1995). Overall, Naff (2001) concludes that "such barriers have adverse consequences" for women and people of color in the federal workplace but that factors such as leadership, perceptions, grievance processes, and organizational culture hold the promise for progress (pp. 223-224). Moreover, minority employees held less favorable views of agency personnel practices and were not only more likely to perceive unfair 
treatment but also more likely than nonminority employees to indicate a favorable attitude on other aspects of the workplace environment (p. 15).

We also hypothesize that older workers, regardless of gender, will be more likely to perceive that they have been victims of sexual harassment (Reese \& Lindenberg, 2005) and have experienced retaliation for whistle-blowing (Parmerlee et al., 1982). These experiences include feeling direct retaliation for refusing to obey an unlawful order; reporting unwanted sexual attention or sexual harassment; disclosing health and safety dangers, and witnessing and reporting unlawful behavior or fraud, waste, or abuse; and testifying for or otherwise assisting any individual in the exercise of whistle-blowing, equal opportunity, or appeal rights. These expectations are driven by the fact that older workers have had longer periods of time to experience or observe these types of employee insults, have less to lose in reporting these behaviors than younger and newer workers on the way up or in midcareer status, and have a better experiential base to judge untoward behaviors.

Likewise, we hypothesize that supervisors are more likely to be satisfied that discrimination has not occurred in the workplace. There are multiple reasons for this expectation. Managers have multiple incentives to put a more positive face on the workplace than do nonsupervisory personnel. These include the possibility that they are the sources of discriminatory behavior, that they have little incentive to report untoward behavior that happens under their watch, and that the sunk costs they have in attaining managerial status makes it more costly career-wise to become whistleblowers. It is also less likely that they will have personally experienced discriminatory behavior given their rise into management.

Finally, we must note that agency of employment is also likely to be a significant predictor of retaliation or discrimination against employees. Indeed, the U.S. Merit Systems Protection Board (MSPB) noted in a 2008 report that agency typically explained variations in employee attitudes more strongly than demographic variables, especially with regard to organizational culture and working conditions (U.S. MSPB, 2008, p. 14). Unfortunately, the relatively low numbers of employees across the federal government who perceive either type of subjective discrimination prevented interagency comparison.

\section{Data and Method}

The data informing the analysis are culled from three versions of the Merit Principles Survey (MPS). Since its inception in 1979, the MSPB has periodically gauged the attitudes of federal workers on a variety of work-related issues. Notably, the MPS has been administered every 3 years or so to measure employee satisfaction, adherence to merit principles in the workplace, and avoidance of prohibited personnel practices (U.S. MSPB, 2008). As such, the perceptions and attitudes gathered from the survey serve as an important bellwether for assessing the state of public management reforms underway during the implementation of the survey. Together with surveys conducted by the U.S. Office of Personnel Management (see Lee, Cayer, \& Lan, 2006), MPS 
data are particularly valuable to researchers because their collection adheres to the highest standards of survey rigor and covers a large population of workers. Most relevant to the present study, MPS data have informed research on adverse personnel experiences (Daley, 2007), employee perceptions of performance appraisals (Daley, 1990), the likelihood of whistle-blowing and retaliation (Miceli, Rehg, Near, \& Ryan, 1999; Near \& Miceli, 2008), and whistle-blowing and its link to public service motivation (Brewer \& Selden, 1998).

We use the 2000 MPS data as a benchmark to assess where employee attitudes stood at the outset of Bush's first term. The 2005 data mark the midpoint of his twoterm tenure in office and may reflect some of the patriotic "bump" resulting from the national solidarity forged by the terrorist attacks in 2001. Finally, the 2007 survey was administered at the end of his second term and provides an opportunity to assess the effects that Bush's policies had in general, and with regard to HRM in particular, on employee attitudes. The 2007 results also serve as a benchmark for the disposition of the federal workforce inherited by the Obama administration.

We identified those questions that remained intact across three administrations of the MSPB, which allowed us to provide a rigorous analysis of changes in employees' attitudes. For the sake of precision, we limited our analysis to only those questions where wording did not change across the 2000, 2005, and 2007 administrations of the MPS. Thus, unlike studies that compare the results of survey questions with similar, but not identical, wording (see Alonso \& Lewis, 2001; Daley, 1990; Lee et al., 2006), our study accounts for concerns of validity by confining the analysis to only those questions whose wording remained constant. While we are assured of the conceptual and statistical comparability of the 3 years of survey results, however, the range of topics included in our study is necessarily confined to those topics whose question phrasing went unchanged. Ultimately, our study was limited to assessing perceptions of inappropriate retaliation and unlawful discrimination.

The MPS asks respondents to indicate their level of agreement with a number of statements evaluating workforce issues in the federal government, including supervision, employee development, and performance management. The data were collected from the sampling frame of randomly selected public employees representing various agencies and departments in the federal workforce. For the 2000 MSPB survey, 17,250 federal employees were queried with a response rate of $43 \%$. The 2005 MSPB survey queried 74,000 federal employees with a response rate of $50 \%$. Finally, for the 2007 MSPB survey, 68,789 federal employees were queried with a $60 \%$ response rate. The 2005 and 2007 surveys were conducted electronically.

\section{Findings}

\section{General Trend}

The first step in analyzing the data from the three MSPB surveys is to examine informally whether there is a change in employee attitudes across the surveys. ${ }^{2}$ Although 
Table I. Descriptive Statistics of Survey Questions Used in Analysis

\begin{tabular}{|c|c|c|c|c|}
\hline Variable & Variable name & $\begin{array}{c}2000 \\
\text { "Yes" (\%) }\end{array}$ & $\frac{2005}{\text { "Yes" (\%) }}$ & $\begin{array}{l}2007 \\
\text { "Yes" (\%) }\end{array}$ \\
\hline \multicolumn{5}{|c|}{$\begin{array}{l}\text { In the past } 2 \text { years, do you feel you have been retaliated against or threatened with retaliation } \\
\text { for taking any of the following actions? }\end{array}$} \\
\hline $\begin{array}{l}\text { Disclosing health and safety } \\
\text { dangers, unlawful behavior, } \\
\text { and/or fraud, waste, and abuse }\end{array}$ & Whistle-blowing & 7.16 & 3.71 & 4.32 \\
\hline $\begin{array}{l}\text { Testifying for or otherwise } \\
\text { assisting any individual in the } \\
\text { exercise of whistle-blowing, equal } \\
\text { opportunity, or appeal rights }\end{array}$ & $\begin{array}{l}\text { Assisting exercise } \\
\text { of right }\end{array}$ & 4.63 & 2.53 & 3.05 \\
\hline Refusing to obey an unlawful order & Refuse to obey & 2.16 & 1.37 & 1.96 \\
\hline $\begin{array}{l}\text { Reporting unwanted sexual } \\
\text { attention or sexual harassment }\end{array}$ & $\begin{array}{l}\text { Reporting sexual } \\
\text { harassment }\end{array}$ & 1.36 & 0.78 & 0.96 \\
\hline \multicolumn{5}{|c|}{$\begin{array}{l}\text { In the past } 2 \text { years, have you been denied a job, promotion, pay increase, or other job benefit } \\
\text { because of unlawful discrimination based on the following factors? }\end{array}$} \\
\hline Race & Race & 13.14 & 6.48 & 4.31 \\
\hline Sex & Sex & 11.67 & 6.49 & 3.76 \\
\hline Age & Age & 10.94 & 7.66 & 4.64 \\
\hline Disability & Disability & 2.33 & 1.70 & I.7I \\
\hline
\end{tabular}

previous MSPB survey results indicate that employees have become less likely to report experiencing such retaliation since 1992 (U.S. MSPB, 2008), the results shown in Table 1 suggest that the overall incidence was lower from 2000 to 2005 but higher for 2007 than for 2005 for all the questions. ${ }^{3}$ For example, the percentage of respondents who felt that they had been retaliated against for refusing to obey an unlawful order dipped from $2.16 \%$ in 2000 to $1.37 \%$ in 2005 , only to rise again to $1.96 \%$ in 2007 . Although these percentages are all relatively small, one can recast the data to say that the 2005 rate is only $63 \%$ of the 2000 results, but the 2007 rate is $91 \%$ of that from 2000. In other words, whatever progress was made between 2000 and 2005 on this indicator of subjective discrimination, the effect had largely evaporated by 2007. These results beg further, more rigorous examination, since "these results on retaliation suggest that work remains to be done in creating a workplace where employees can raise concerns about organizational priorities, work processes, and personnel policies and decisions without fear of retaliation" (U.S. MSPB, 2008, p. 50).

A more consistent trend is observed for the questions related to perceptions of discrimination, as there is a consistent decrease in the percentages for race, sex, and age from 2000 to 2007. Such results suggest that the federal government has made considerable progress in creating organizational climates that are perceived as having fewer, and few, instances of discrimination. A notable example is perceptions of discrimination 
on the basis of race, which steadily declined from $13.14 \%$ in 2000 to only $4.31 \%$ in 2007. Nevertheless, the trends must be interpreted with considerable caution, since attitudes related to subjective discrimination are likely to vary considerably based on employee demographics (see especially Naff, 2001).

\section{Accounting for Demographic Differences}

Since the dependent variables used in this analysis are categorical (ordinal) variables and thus lack the continuous normal distribution assumed for ordinary least squares regression, logistic regression is used to account for the dichotomous nature of the dependent variables. ${ }^{4}$ Employing this technique ensures accurate specification of the models. ${ }^{5}$ In addition, we included interaction terms for the supervisor variable and the controls for gender and race. Our assumption is that perceptions of reprisal and discrimination will be more common for women and minority respondents. Research regarding pay and promotion inequities in the public workforce indicates that there are clear differences with respect to race (Aufrecht, 1999; Page, 1994; Sisneros, 1993) and women (Bays, 1991; Guy, 1993; Guy \& Newman, 2004, 2005; Mani, 2001; Naff, 1994; Saltzstein, 1986), with rates for both protected groups often lagging behind those of majority employees, especially in senior-level positions.

The first set of logistic regression models assesses perceptions of inappropriate reprisals for whistle-blowing; assisting another individual in the exercise of whistleblowing, equal opportunity, or appeal rights; refusing to obey an unlawful order; or reporting unwanted sexual attention or sexual harassment (see appendix). Independent variables include supervisory status, gender, age, length of service, education level, and race. Interaction variables are included to account for supervisory status and gender and supervisory status and race. The second set of models analyzes perceptions of illegal discrimination on the bases of race, sex, age, and disability using the same controls. ${ }^{6}$

\section{Reprisal Results}

The results of the logistic models examining the reprisal dependent variables are reported in Tables 2, 3, and 4 for each survey year, respectively. ${ }^{7}$ The likelihood ratios $\left(\chi^{2}\right)$ indicate that the models as a whole are statistically significant; thus, it is extremely unlikely that these results are due to chance. We have included the factor change in odds statistics for a more substantive assessment of the effects of the logit model. The inclusion of the $\operatorname{Exp}(b)$ scores allows us to interpret the odds of observing a positive outcome, holding all other variables constant (Long \& Freese, 2006). Turning to the results of the logistic regressions for the reprisal models, we see that they are consistent across the survey years for the supervisory status variable, the race variable, and the interaction term for supervisory status and gender. Regarding race, we see that minorities in the federal workforce consistently express the view that they have been retaliated against or threatened with retaliation in the exercise of their rights and refusal to obey unlawful orders for all 3 survey years. Indeed, the $\operatorname{Exp}(b)$ statistics 


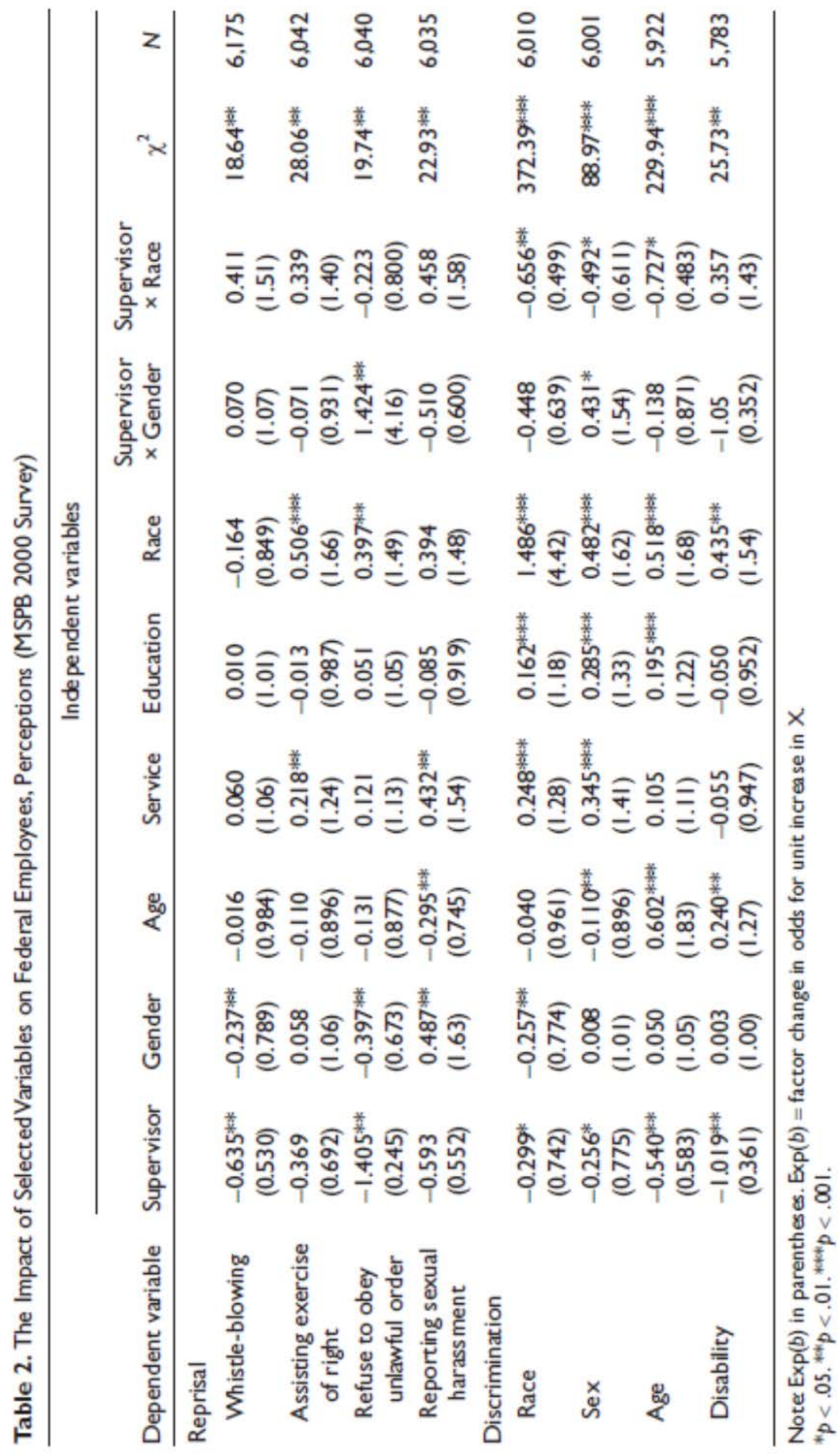




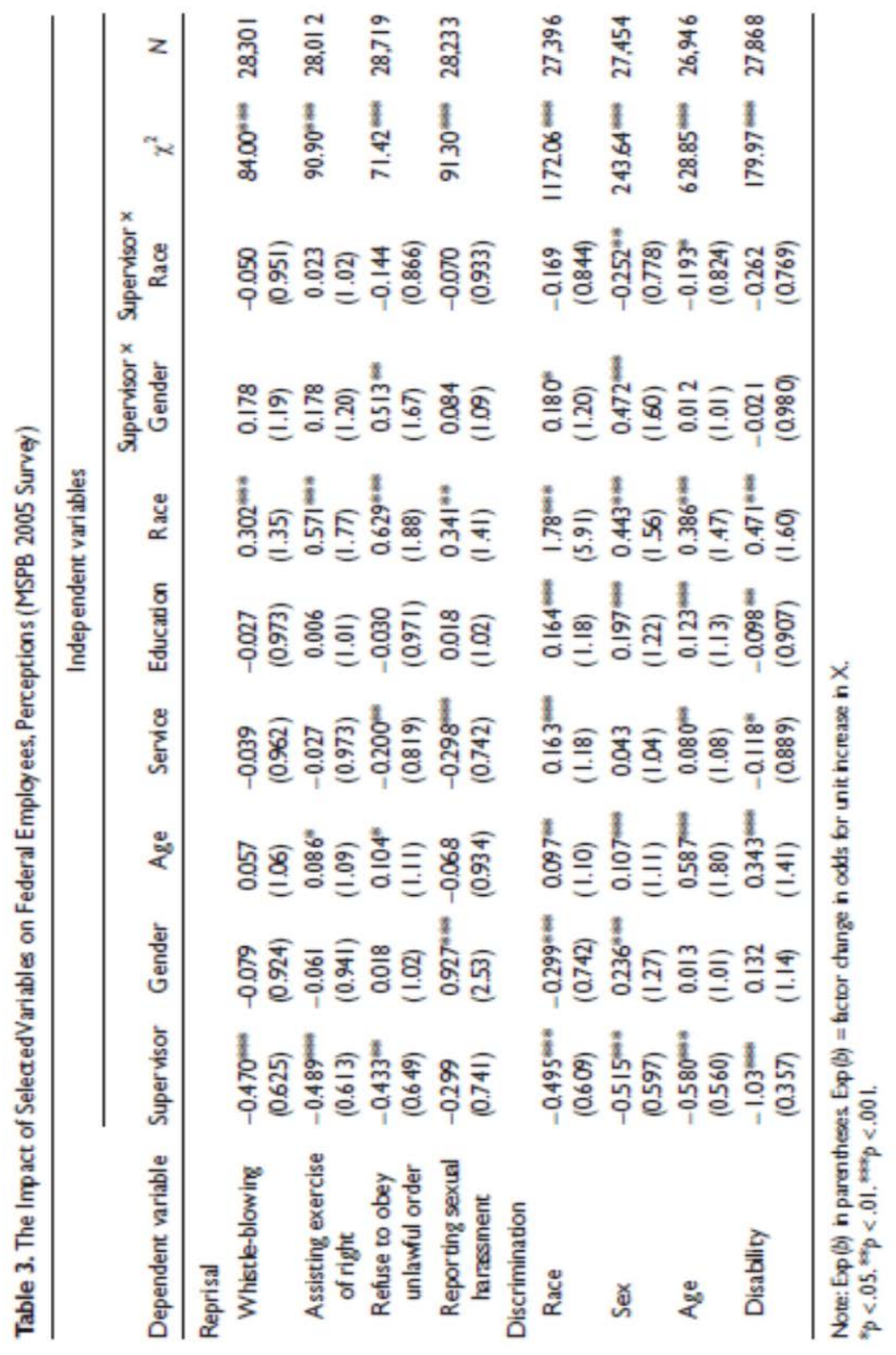




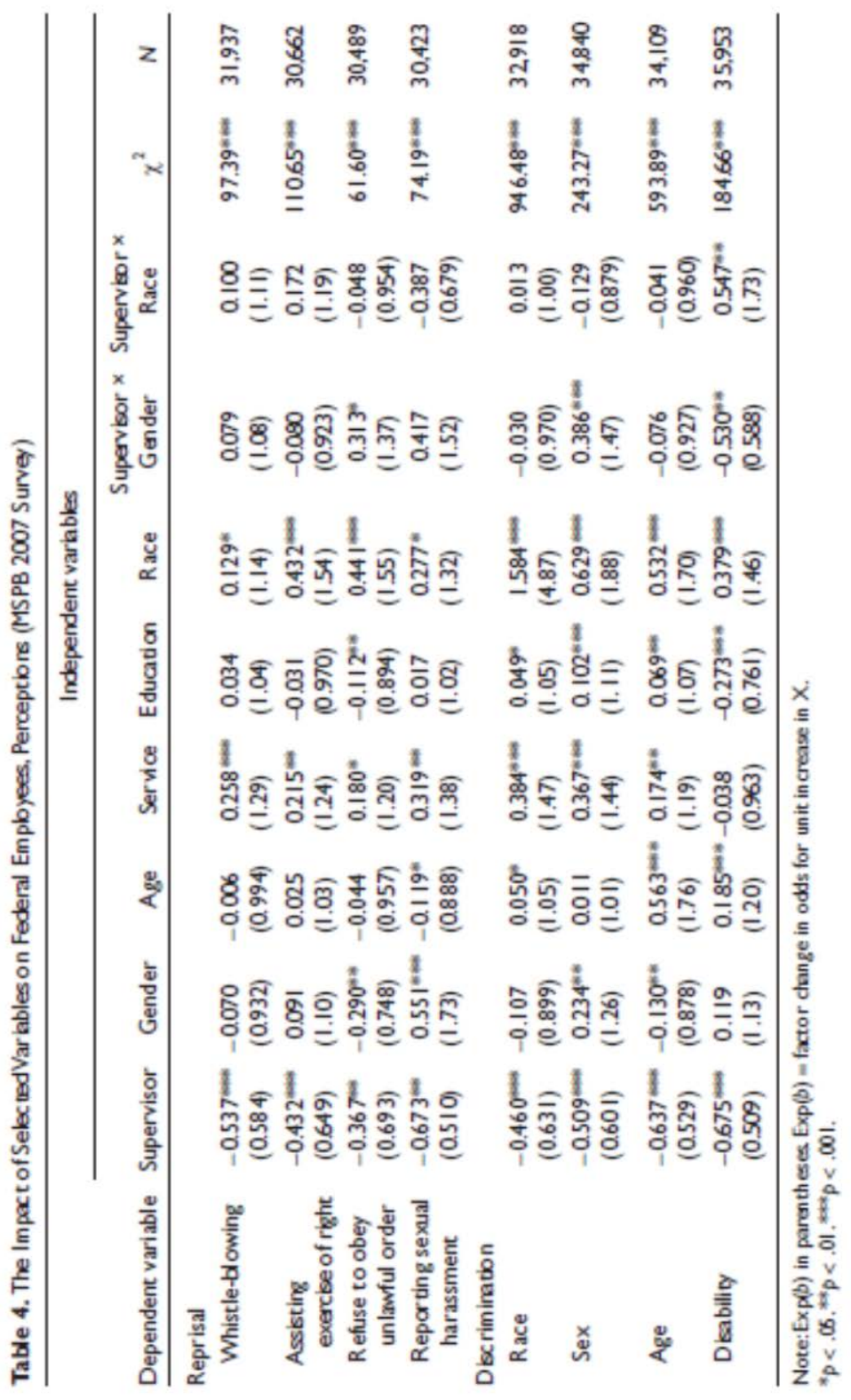


for 2000 indicate that minorities were 1.66 and 1.49 times more likely to feel that they were retaliated against in the exercise of their rights and refusal to obey unlawful orders, respectively. Minorities echoed similar perceptions in Tables 3 and 4, with results indicating that these respondents were 1.77 and 1.88 times more likely in 2005 and 1.54 and 1.55 times more likely in 2007 to perceive that they had been retaliated against or threatened in the exercise of their rights and refusal to obey unlawful orders. For 2005 and 2007, these same respondents additionally felt that they were retaliated against or threatened with retaliation when disclosing improprieties (whistle-blowing) and reporting instances of sexual harassment.

With respect to the interaction term for female supervisors, it would appear that across the 3 years, these respondents felt that they had been retaliated against or threatened with retaliation when refusing to obey an unlawful command. In fact, female supervisors were $4.16,1.67$, and 1.37 times more likely than their male counterparts to have indicated either being retaliated against or threatened with retaliation for the refusal to obey an unlawful command for each of the survey years, respectively. In contrast, the supervisor respondents across the 3 survey years appeared to be sanguine about the federal workplace and reprisals for taking certain actions. Supervisor respondents were significantly less likely to report having been threatened with or experiencing retaliation in the workplace regarding the four reprisal variables. For example, supervisors in general were less likely to feel retaliated against or threatened with retaliation for refusing to obey an unlawful command by a factor of .245 , .649, and .693 for 2000, 2005, and 2007, respectively, in contrast with the perceptions of female supervisor respondents as indicated above for the same independent variable. It would seem that there is a disconnect between supervisors and their subordinates and that such discord would appear to be especially true of minority respondents and female supervisors.

With respect to the other control variables, we see a number of significant findings, but the results lack consistency across the 3 years. Regarding gender, we find a consistent result with respect to reprisals and the reporting of instances of sexual harassment. Female respondents were 1.63, 2.53, and 1.73 times more likely than their male counterparts to perceive that they had been retaliated against or threatened with retaliation for reporting instances of sexual harassment in 2000, 2005, and 2007, respectively. It would seem that female federal employees tend to feel threatened with retaliation or retaliated against when reporting sexual harassment in the workplace. The results for the other reprisal variables are less consistent for the gender variable.

Turning to age and service, there would appear to be less consistent results across the 3 survey years. One point of interest is the statistic related to tenure in public service ("service") and reprisal with respect to reporting cases of sexual harassment. Although the variable is consistently significant across the 3 survey years, for 2005 the coefficient is negative in contrast to the positive statistics in the other 2 survey years. Thus, while seasoned respondents were 1.54 and 1.38 times more likely to feel retaliated against or threatened with retaliation in 2000 and 2007, the odds decreased in 2005 by a factor of .742. Education in the 3 survey years is not a significant predictor of reprisal issues. 


\section{Discrimination Results}

The results of the logistic models examining the discrimination dependent variables are reported in Tables 2, 3, and 4 for each survey year, respectively. As with the reprisal models, the likelihood ratios $\left(\chi^{2}\right)$ are statistically significant. Perusing the findings for discrimination, we see consistent results with the variables for supervisor, age, education, and race. With respect to age, the data across the 3 survey years illustrate that older respondents tend to feel discriminated against with regard to their age and disability for certain human resource decisions-namely, pay, promotion, and benefits. Turning to education, it would seem that more educated respondents in all 3 survey years tend to feel that they have experienced discrimination in matters of pay, promotion, and benefits with respect to race, sex, and age. Perhaps the more educated respondents are better informed when it comes to issues of discrimination and thus more likely to know when it is occurring and when to report such acts. Finally, the race variable is consistent across the 3 survey years for all 4 types of discrimination tested. It would seem that minority respondents tend to feel that they have been discriminated against in matters of pay, promotion, and benefits based on their race, sex, age, or disability.

Turning to the $\operatorname{Exp}(b)$ scores, we see that minority respondents are 4.42, 5.91, and 4.87 times more likely to have experienced discrimination regarding pay, promotion, and benefits for each of the survey years. Given findings elsewhere indicating real pay inequities in the public service (Aufrecht, 1999; Page, 1994; Sisneros, 1993) regarding race, the perceptions of minorities illustrated here are an important finding. Perhaps minority respondents, similar to the more educated respondents, are more aware of discriminatory law and policy in the workplace given historical antecedents with respect to discrimination in the public sector. Thus, minorities may be more likely to acknowledge and report instances of discrimination.

With respect to the interaction terms, once again we see a consistent finding with regard to female supervisors. In the case of discrimination, it would appear that female supervisor respondents are more likely to have experienced discrimination in matters of pay, promotion, or benefits with respect to their gender status. Yet the models indicate that supervisors in general tend to be more optimistic with regard to the perception of discrimination in the workplace. Clearly, supervisor opinions differ when accounting for gender in the interaction term. The $\operatorname{Exp}(b)$ scores for discrimination based on gender (sex) lend credence to this divergence in perceptions. Statistical significance is achieved across all 3 survey years, with women supervisors $1.54,1.60$, and 1.47 times more likely to feel discriminated against regarding pay, promotion, or benefits for each respective year.

This would seem to be an obvious finding, but nonetheless an important one given the literature addressing pay inequities in government based on gender (Bays, 1991; Guy, 1993; Guy \& Newman, 2004, 2005; Hale, 1996; Lewis, 1998; Mani, 2001; Naff, 1994; Saltzstein, 1986). It would appear that women supervisors are less than sanguine than their male colleagues about their prospects for pay 
promotion, and benefits based on attested instances of sex discrimination in the federal workplace. Given these findings, clearly much more needs to be done regarding breaking the "glass-ceiling" barrier and comparable worth issues in the public sector.

\section{Conclusions: The Dog That Didn't Bark- But Still Needs Attention}

As the editors of this symposium note, George W. Bush's big government conservative agenda placed him within the category of presidents that Skowronek (2008) calls "orthodox innovators." Like similarly situated presidents in political time, Bush was convinced that the principles of the Reagan Revolution were correct but in need of updating in light of changed circumstances. Otherwise, the partisan political realignment sought by Reagan and interrupted by the Clinton years in favor of a Republican majority could not be completed and might even be squandered. And critical among Bush's "orthodox innovations” was the privileging of managerial prerogatives over those of public employees, shifting from bureaucratic cultures animated by affirmative action to ones empowered by equal opportunity, and doing all this while ensuring that employee rights remained intact.

The preceding analysis speaks directly to the question of what the impact of these efforts was on federal employee perceptions of subjective discrimination with regard to several key components of federal personnel management. It offers both good news and bad news. Taking the former first, it appears as though the push for big government conservatism that envisioned an enhancement of managerial prerogative and equality of opportunity as opposed to equality of outcome did not come at the price of employees' perceptions that their work protections were compromised. In fact, overall, our analysis suggests that the federal government seems to be developing organizational cultures that are less likely to engender discriminatory behaviors than was the case at the start of the George W. Bush presidency. The overall trends for all indicators of subjective discrimination point to a consistent decline in perceptions of discrimination across the Bush years and a decline for all problematic behaviors studied in this article. Whether this occurred because the Bush administration sought to improve the protection of worker rights at the same time that it pressed for weakening the power of employee unions cannot be discerned from our analysis. It is quite possible that momentum created over the decades was so powerful and institutionalized that the Bush administration could not gain traction for its efforts to privilege managers over subordinates and limit employee rights. Sorting this out offers an avenue of future research that merits attention.

That said, the disturbing news is that there also are notable upticks in perceptions of retaliation from 2005 to 2007, indicating that future MPSs must continue to reassess the state of these issues. Although our analysis rightly suggests that the federal government is becoming an increasingly comfortable place for minority and female employees, the 
ultimate goal of a discrimination-free environment remains elusive. Such caution is especially warranted in light of the analysis that accounts for the demographics and supervisory status of respondents to the MSPB surveys. Minority employees consistently indicated that they have been the targets of retribution for participating in a range of legally protected activities related to bringing improprieties in the workplace to light. Female respondents indicated ongoing retaliation for reporting instances of sexual harassment. As we posited, nonsupervisory employees were much more likely than supervisors to perceive a recurrent problem with retaliation. Such a hierarchically based division of attitudes is a clear sign that much work needs to be done to address discordant perceptions of subjective discrimination in the federal workplace. This observation is strengthened by the further disparity of attitudes of female supervisors from their male colleagues on the issue of reprisals for refusing to obey an unlawful order.

Demographically based attitudinal differences also are found for questions concerning discrimination. Minorities perceive that denials of jobs, promotions, pay increases, and other benefits due to unlawful discrimination occur on the basis of race, sex, age, and disability. Such a pattern indicates an unmistakable problem for managers. If one accepts the axiom that "perception is reality," then the federal workplace has an intransigent problem with discrimination related to personnel decisions. The justification for such an indictment is further evidenced by the pattern of increasing educational levels of employees being consistently associated with perceptions of discrimination on the basis of race, sex, and age. Turning to gender, female employees became increasingly concerned about sex-based discrimination from 2000 to 2007. Importantly, female supervisors were much more likely than their male counterparts to perceive such a problem. These results point to an attitudinal divide that must be bridged if concerns over glass ceilings and pay inequity are finally to be overcome.

Only with a similar assessment of employee attitudes during the subsequent Obama administration will the relationship between attitudes and personnel reforms become clear. Nevertheless, this contribution to the symposium demonstrates the dual realities that much progress has been made to bring the federal workplace ever closer to the goal of being discrimination free, but that significant issues remain to be addressed. Of course, a research design that accounts for both employee perceptions of discrimination as well as independent indicators of actual discriminatory practices would be ideal. Nevertheless, our study sheds new light on the topic by directly comparing attitudes on the same questions across three administrations of an expansive and reliable government-wide survey. As such, we conclude that the Obama administration inherits a federal workplace with lingering attitudinal disparities that likely serve as an indicator of the types of HRM issues that will continue to demand attention in the coming decades. Continued efforts to examine trends in federal employee attitudes, as measured by the MSPB and the Office of Personnel Management, will serve as invaluable indicators of emerging challenges for HRM more generally. 


\section{Appendix \\ Questions and Variable Coding}

\section{Dependent Variables}

Reprisal. In the past 2 years, do you feel you have been retaliated against or threatened with retaliation for taking any of the following actions? Respondents were given the following choices: "no"; "yes, experienced retaliation"; "yes, threatened with retaliation"; and "not applicable.” MSPB coded these data so that both "yes" responses were combined. For purposes of our analysis, the combined "yes" responses were coded 1, "no" responses were coded 0 , and "not applicable" responses were coded as missing.

Whistle-blowing: Disclosing health and safety dangers, unlawful behavior, and/ or fraud, waste, and abuse.

Assisting exercise of right: Testifying for or otherwise assisting any individual in the exercise of whistle-blowing, equal opportunity, or appeal rights.

Refusing to obey an unlawful order.

Reporting unwanted sexual attention or sexual harassment.

Discrimination. In the past 2 years, have you been denied a job, promotion, pay increase, or other job benefit because of unlawful discrimination based on the following factors? Respondents were given the following choices: "yes"; "no"; and "don't know." "Yes” responses were coded 1, "no" responses were coded 0, and "don’t know” responses were coded as missing.

\section{Race/national origin}

Sex

Age

Disability

\section{Independent Variables}

Supervisor. Supervisor status—coded 1 = supervisor, 2 = employee (nonsupervisory).

Gender. Coded 1 = female, $0=$ male.

Age. Coded $1=29$ or younger, $2=30-39,3=40-49,4=50-59,5=60$ or older.

Service. Federal civilian service-coded $1=$ less than 1 year, $2=1-3$ years, $3=4-9$ years, $4=10-29$ years, $5=30$ or more years.

Education. Coded 1 = less than high school, 2 = high school, $3=$ more than high school but less than a 4-year college degree, $4=4$-year college degree, $5=$ master's or professional degree or higher.

Race. Ethnicity/race/national origin—coded 1 = minority (includes American Indian or Alaskan Native, Asian/Hawaiian/Pacific Islander, Black, Hispanic), 0 = White. 


\section{Acknowledgments}

The authors would like to thank the staff of the U.S. MSPB's Office of Policy and Evaluation for their assistance with the survey data used in this analysis. More generally, they would like to show their appreciation for the MSPB's tireless advocacy on behalf of civil servants, the merit system, and the foundational principles of public human resource management.

\section{Declaration of Conflicting Interests}

The authors declared no potential conflicts of interest with respect to the authorship and/or publication of this article.

\section{Funding}

The authors received no financial support for the research and/or authorship of this article.

\section{Notes}

1. It is important to note that we analyze those employees who perceived they were the victims of retaliation and/or discrimination, irrespective of whether they actually, for example, engaged in the formal whistle-blowing process or submitted a discrimination claim. In other words, an employee may have brought misdeeds by colleagues to the attention of a manager and then came to believe that they were the victim of retaliation for such action. The employee may not have used the formal whistle-blowing process but nonetheless felt victimized by their actions. Our contention is that such perceptions present a managerial challenge whether a formal process was triggered, even though the triggering of the formal process may be a necessary component of an actionable legal claim of discrimination. Thus, subjective discrimination can have adverse effects on the workplace whether a successful grievance of objective discrimination could result.

2. Merging or combining the data sets and attempting to control for time period would be one option for assessing change from year to year regarding the control variables. Creating dummy variables for each year, using 2000 as a base category, would allow us to employ two dummy variables for 2005 and 2007 that could be compared with 2000. Thus, the 2005 coefficient would determine whether there is a significant difference between respondents from 2005 versus those from 2000. The same would be true for 2007 versus 2000. If there are significant differences on this variable, it means that time has some influence across samples. Unfortunately, the data collection prevents us from applying this technique. As stratified sampling was used in the data collection, a variable was calculated to weight each response/stratum in proportion to its share of the workforce, so that "government-wide" response distributions could be calculated. As such, weights were calculated separately for each survey year, constraining tabulations and analyses by year instead of allowing for the "collapsing” of data across years.

3. As seen in Table 1, the relatively low numbers of employees across the federal government who perceived either type of subjective discrimination prevented interagency comparison. 
4. For each of the dependent variables employed in the research presented here, respondents were asked to indicate their level of agreement with the statement from the survey by indicating “yes,” “no,” or “don’t know.” "Don’t know” responses were excluded as missing for purposes of the analysis. Variables used in this research and their coding are included in the appendix.

5. The MSPB employed stratified samples for each year of the MPS included here, with (generally) higher sampling rates for supervisors and for smaller agencies. To calculate government wide response distributions, weights were calculated to weight each response/stratum in proportion to its share of the workforce. The weight variable is not reported in the results presented here but was included in each regression.

6. To ensure that our models do not violate basic assumptions of logistic regression, several diagnostic procedures were implemented, including a check for multicollinearity using Spearman correlations. Spearman correlations are more appropriate for categorical variables because the technique does not assume a linear relationship between variables. Spearman correlations aided in hypotheses testing and the development of the models employed. The variables for reprisal and discrimination were the only policy areas consistent throughout the three data sets. Results for the Spearman correlations were excluded due to space limitations but can be provided on request.

7. While one may assume that there is a clear difference between respondents indicating that they experienced retaliation versus those who were merely threatened, we feel that either incident can impact the harmony of the workplace environment (see appendix for coding). Thus, an employee who is threatened may not face immediate retribution but may feel the lingering effects of the threat in their job performance. This may be especially true for minorities who have experienced a history of mistreatment in the public sector workforce. Therefore, we have combined the "yes" responses in our analyses.

\section{References}

Alonso, P., \& Lewis, G. B. (2001). Public service motivation and job performance: Evidence from the federal sector. American Review of Public Administration, 31, 363-380.

Aufrecht, S. E. (1999). Missing: Native American governance in American public administration literature. American Review of Public Administration, 29, 370-390.

Bays, J. H. (1991). Women in public administration in the United States. Women and Politics, 11(4), 85-109.

Brewer, G. A., \& Selden, S. C. (1998). Whistle blowers in the federal civil service: New evidence of the public service ethic. Journal of Public Administration Research and Theory, 8, 413-439.

Daley, D. M. (2007). If a tree falls in the forest: The effect of grievances on employee perceptions of performance appraisal, efficacy, and job satisfaction. Review of Public Personnel Administration, 27, 281-296.

Daley, D. M. (1990). The Civil Service Reform Act and performance appraisal: A research note on federal employee perceptions. Public Personnel Management, 19, 245-251.

Guy, M. E. (1993). Three steps forward, two steps backward: The status of women's integration into public management. Public Administration Review, 53, 285-291. 
Guy, M. E., \& Newman, M. A. (2005). Valuing diversity: The changing workplace. In S. E. Condrey (Ed.), Handbook of human resource management in government (2nd ed., pp. 143-163). San Francisco: Jossey Bass/Wiley.

Guy, M. E., \& Newman, M. A. (2004). Women's jobs, men’s jobs: Sex segregation and emotional labor. Public Administration Review, 64, 289-298.

Hale, M. E. (1996). Gender equality in organizations: Resolving the dilemmas. Review of Public Personnel Administration, 16(1), 7-18.

Hopkins, A. H. (1980). Perceptions of employment discrimination in the public sector. Public Administration Review, 40(2), 131-137.

Jackson v. Birmingham Board of Education, 544 U.S. 167 (2005).

Jackson, R. A., \& Newman, M. A. (2004). Sexual harassment in the federal workplace revisited: Influences on sexual harassment by gender. Public Administration Review, 64, 705-717.

Lee, H., Cayer, N. J., \& Lan, G. Z. (2006). Changing federal government employee attitudes since the Civil Service Reform Act of 1978. Review of Public Personnel Administration, 26(1), 21-51.

Lewis, G. B. (1998). Continuing progress toward racial and gender pay equality in the federal service: An update. Review of Public Personnel Administration, 18(2), 23-40.

Long, J. S., \& Freese, J. (2006). Regression models for categorical dependent variables using STATA (2nd ed.). College Station, TX: Stata.

Mani, B. G. (2001). Women in the federal civil service: Career advancement, veterans' preference, and education. American Review of Public Administration, 31, 313-339.

Miceli, M. P., Rehg, M., Near, J. P., \& Ryan, K. C. (1999). Can laws protect whistle-blowers? Results of a naturally occurring field experiment. Work and Occupations, 26, 129-151.

Mitchell, C. E. (2009). Retaliation lawsuits held applicable for federal employees under the Age Discrimination in Employment Act: A victory for older federal workers. Review of Public Personnel Administration, 29(1), 89-94.

Naff, K. C. (2001). To look like America. Boulder, CO: Westview.

Naff, K. C. (1995). Perceptions of discrimination: Moving beyond the numbers of representative bureaucracy. Policy Studies Journal, 23, 483-498.

Naff, K. C. (1994). Through the glass ceiling: Prospects for the advancement of women in the federal civil service. Public Administration Review, 54, 507-514.

Near, J. P., \& Miceli, M. P. (2008). Wrongdoing, whistle-blowing, and retaliation in the U.S. government: What have researchers learned from the Merit Systems Protection Board (MSPB) survey results? Review of Public Personnel Administration, 28, 263-281.

Newman, M. A., Jackson, R. A., \& Baker, D. D. (2003). Sexual harassment in the federal workplace. Public Administration Review, 63, 472-483.

Page, P. (1994). African-Americans in executive branch agencies. Review of Public Personnel Administration, 14(1), 24-51.

Parmerlee, M. A., Near, J. P., \& Jensen, T. C. (1982). Correlates of whistle-blower's perceptions of organizational retaliation. Administrative Science Quarterly, 27(1), 17-34.

Reese, L. A., \& Lindenberg, K. E. (2005). Gender, age, and sexual harassment. Review of Public Personnel Administration, 25, 325-352. 
Saltzstein, G. H. (1986). Female mayors and women in municipal jobs. American Journal of Political Science, 30, 140-164.

Sisneros, A. (1993). Hispanics in the public service in the late 20th century. Public Administration Review, 53(1), 1-7.

Skowronek, S. (2008). Presidential leadership in political time: Reprise and reappraisal. Lawrence: University Press of Kansas.

U.S. Equal Employment Opportunity Commission. (2008). Charge statistics: FY 1997 through FY 2008. Retrieved November 12, 2009, from http://eeoc.gov/eeoc/statistics/

U.S. Merit Systems Protection Board. (2008). The federal government: A model employer or a work in progress? Washington, DC: Author.

\section{Bios}

Mark D. Bradbury (bradburymd@appstate.edu) is the interim director of the MPA program at Appalachian State University, Boone, North Carolina. His research has appeared in a number of public administration journals, including the Review of Public Personnel Administration, the Journal of Public Administration Research and Theory, and the American Review of Public Administration.

R. Paul Battaglio, Jr. (battaglio@utdallas.edu) is an associate professor in the Public Affairs Program at The University of Texas at Dallas. Among his many research interests are public human resource management, public opinion and public policy, and privatization. His work has appeared in Public Administration Review, the Journal of Public Administration Research and Theory, and the American Review of Public Administration.

John L. Crum (john.crum@mspb.gov) is the director of policy and evaluation at the U.S. Merit Systems Protection Board. As such, he oversees the board's statutory mission to conduct studies of federal human resources management policies and programs to determine if they are operating in accord with statutory merit systems principles and achieving their intended purposes. 